\title{
Glycophenotype Evaluation in Cutaneous Tumors Using Lectins Labeled with Acridinium Ester
}

\author{
Luiza Rayanna Amorim Lima, ${ }^{1}$ Matheus Filgueira Bezerra, ${ }^{1}$ \\ Sinara Mônica Vitalino Almeida, ${ }^{1,2}$ Lúcia Patrícia Bezerra Gomes Silva, ${ }^{1}$ \\ Eduardo Isidoro Carneiro Beltrão, ${ }^{1,3}$ and Luiz Bezerra Carvalho Júnior ${ }^{1,3}$ \\ ${ }^{1}$ Laboratório de Imunopatologia Keizo Asami (LIKA), Universidade Federal de Pernambuco, Cidade Universitária, \\ 50030 Recife, PE, Brazil \\ ${ }^{2}$ Faculdade de Ciências, Educação e Tecnologia de Garanhuns (FACETEG), Universidade de Pernambuco (UPE), \\ 50100 Garanhuns, PE, Brazil \\ ${ }^{3}$ Departamento de Bioquímica, Universidade Federal de Pernambuco, Cidade Universitária, 50030 Recife, PE, Brazil
}

Correspondence should be addressed to Luiz Bezerra Carvalho Júnior; lbcj@hotlink.com.br

Received 27 March 2013; Revised 13 June 2013; Accepted 21 June 2013

Academic Editor: Timothy M. Block

Copyright (C) 2013 Luiza Rayanna Amorim Lima et al. This is an open access article distributed under the Creative Commons Attribution License, which permits unrestricted use, distribution, and reproduction in any medium, provided the original work is properly cited.

\begin{abstract}
Background. Tumor cells show alterations in their glycosylation patterns when compared to normal cells. Lectins can be used to evaluate these glycocode changes. Chemiluminescence assay is an effective technique for quantitative analysis of proteins, nucleic acids, and carbohydrates due to its high sensitivity, specificity, and rapid testing. Objective. To use histochemiluminescence based on lectin conjugated to acridinium ester (AE) for the investigation of glycophenotype changes in cutaneous tumors. Methods. Concanavalin A (Con A), Peanut agglutinin (PNA), Ulex europaeus agglutinin-I (UEA-I), and Maackia amurensis agglutinin (MAA) were conjugated to acridinium ester. Biopsies of cutaneous tumors and normal skin were incubated with the lectins-AE, and chemiluminescence was quantified and expressed as Relative Light Units (RLU). Results. Actinic keratosis (AK), keratoacanthoma (KA), squamous cell carcinoma (SCC), and basal cell carcinoma (BCC) showed lower expression of $\alpha$-D-glucose/mannose and $\alpha$ L-fucose residues compared to normal tissue. Cutaneous tumors displayed higher expression of Gal- $\beta(1-3)$-GalNAc residues than normal tissue. AK and SCC exhibited higher expression of Neu5Ac- $\alpha(2,3)$ Gal residues than normal epidermis. KA and BCC showed equivalent RLU values compared to normal tissue. Conclusions. Lectin histochemiluminescence allowed quantitative assessment of the carbohydrate expression in cutaneous tissues, contributing to eliminate the subjectivity of conventional techniques used in the histopathological diagnosis.
\end{abstract}

\section{Introduction}

Nearly all types of malignant cells and many types of diseased tissue cells demonstrate alterations in their glycosylation patterns when compared to their normal counterparts [1]. Alterations in glycosyltransferases expression, sugar nucleotide donors, and disruption of the Golgi contribute to the development of diseases, such as hereditary disorders, immune deficiencies, cardiovascular disease, and cancer [2, $3]$. In the tumor environment, underexpression, truncation or altered branching patterns of certain glycans, and/or changes in glycosylation allow neoplasm cells to usurp many of the events that occur in development such as receptor activation, cell adhesion, and cell motility, which permits tumor cells to invade and spread throughout the organism [4]. The investigation of lectin-carbohydrates interactions is necessary for the understanding of both the glycophenotype and the behavior of the tumor during its differentiation and confirms the hypothesis that biochemical changes in the cell are events that may signal the cell differentiation [5].

Lectins have been used to evaluate the glycophenotype in skin tissues [6-9]. Lectin histochemistry based on colorimetric detection has been used as a supporting tool for differential diagnosis for skin lesions, but this technique only 
permits qualitative or semiquantitative analyses of carbohydrates expression. Thus, quantitative analyses require a sensitive detection that permits an objective and quantitative evaluation of the bound lectin.

Chemiluminescence (CL) analyses represent a powerful tool in life sciences, offering high detectability and specificity $[10,11]$ and allowing low limits of detection (attomole-zeptomole) and versatility [12]. It is a promising and effective technique for quantitative analysis of proteins, nucleic acids, and carbohydrates [13-15]. Therefore, this approach combined with lectin histochemistry could be valuable to reduce the subjective evaluation.

Acridinium ester (AE) compounds quickly outperformed luminol and isoluminol in chemiluminescence for their low detection limits (attomolar range) and specificity [16]. Exposure of $\mathrm{AE}$ label to an alkaline hydrogen peroxide solution triggers a flash of light. AE forms an unstable dioxetane yielding $\mathrm{N}$-methylacridone and produces light at a wavelength of $470 \mathrm{~nm}[17]$.

The skin tumors comprise mainly basal cell carcinoma (BCC), squamous cell carcinoma (SCC), keratoacanthoma (KA), and actinic keratosis (AK). Nonmelanoma skin cancers are the most common form of cancer and their incidence has been increasing considerably. These tumors are rarely fatal but are considered to be fast growing and if neglected may be locally and functionally destructive [18]. The diagnosis of skin neoplasias becomes inaccurate, in some cases, due to a variety of factors that affect the test accuracy, such as a huge spectrum of tumors and their variants and the lower differentiation [8].

Here lectins conjugated to $\mathrm{AE}$ were used to evaluate the glycophenotype in tissues from cutaneous tumors based on the chemiluminescence approach. The biological relevant carbohydrate residues $\alpha$-D-glucose/mannose, Gal- $\beta(1$ $3)$-GalNAc, $\alpha$-L-fucose, and Neu5Ac- $\alpha(2,3)$ were evaluated, respectively, by using the lectins Concanavalin A (Con A), Peanut agglutinin (PNA), Ulex europaeus agglutinin-I (UEAI), and Maackia amurensis agglutinin (MAA).

\section{Material and Methods}

2.1. Reagents. $N$-hydroxysuccinimide-activated dimethyl acridinium ester ((DMAE-NHS)/1966-1-53-2/Organic Lab) was kindly supplied by Dr. H. H. Weetall. Con A, PNA, UEA-I, MAA, N,N-dimethylformamide, trypsin from porcine pancreas, methyl- $\alpha$-D-mannoside, D-galactose, $\alpha$-L-fucose, n-acetylneuraminic acid, and Sephadex G-25 were purchased from Sigma-Aldrich (St. Louis, MO, USA). Chemiluminescent detection was performed using Siemens Reagent TSH 500T (Siemens Medical Solutions Diagnostics, Malvern, PA, USA) composed of $0.5 \% \mathrm{H}_{2} \mathrm{O}_{2}$ in $0.1 \mathrm{~N} \mathrm{HNO}_{3}$ and $0.25 \mathrm{M} \mathrm{NaOH}$. Xylene and ethanol were obtained from Merck (Darmstadt, Germany). All other chemical reagents used were of analytical grade.

2.2. Samples. Skin fragments were obtained through paraffin-embedded biopsies from the Tissue Bank of the Clinic Hospital at the Federal University of the State of Pernambuco (UFPE), Northeastern Region of Brazil, and diagnosed as basal cell carcinoma $(\mathrm{BCC}=17)$, squamous cell carcinoma
$(\mathrm{SCC}=13)$, keratoacanthoma $(\mathrm{KA}=13)$, and actinic keratosis $(\mathrm{AK}=9)$. The diagnosis of skin neoplasms was performed by Dr. Mariana Silva. The normal human epidermis fragments $(\mathrm{NE}=14)$ were obtained from individuals submitted to plastic surgery and supplied from Hospital Santa Clara, Recife, PE, Brazil. The diagnosis of the cutaneous tumors was based on histopathology. This study was approved by the Health Science Centre Bioethical Board from the Federal University of Pernambuco, Brazil (CEP/CCS/UFPE no. 195/09).

2.3. Lectins Conjugation with AE. Lectins ( $1 \mathrm{~mL}$ containing $2 \mathrm{mg}$ of protein) were incubated with $10 \mu \mathrm{L}$ of acridinium ester solution $(0.2 \mathrm{mg}$ diluted in $400 \mu \mathrm{L}$ of N,Ndimethylformamide) for $1 \mathrm{~h}$ at $25^{\circ} \mathrm{C}$ under rotary stirring. The conjugate (lectin-AE) was applied to a column of Sephadex G-25 $(10 \times 1 \mathrm{~cm})$, previously equilibrated with $10 \mathrm{mM}$ phosphate buffer, containing $0.15 \mathrm{M} \mathrm{NaCl}$ (PBS), $\mathrm{pH} 7.2$, and eluted with this buffer. Aliquots $(1 \mathrm{~mL})$ were collected and their protein content was spectrophotometrically determined at $280 \mathrm{~nm}$. The aliquots corresponding to the protein peak had their chemiluminescence assayed. After conjugation, Con A-AE, PNA-AE, and MAA-AE were evaluated regarding the maintenance of their carbohydrate recognition property (hemagglutinating activity) using glutaraldehyde treated rabbit erythrocytes and human erythrocytes for UEA-AE according to Beltrão et al. [19]. Protein concentration was measured according to Lowry et al. [20].

2.4. Chemiluminescent Lectin-Histochemistry. Paraffin sections $(8 \mu \mathrm{m})$ of samples were cut, transferred to glass slides, deparaffinized in xylene, and rehydrated in graded alcohols $(3 \times 100 \%$ and $1 \times 70 \%-10$ dips each). Slices were treated with $0.1 \%(\mathrm{w} / \mathrm{v})$ trypsin solution at $37^{\circ} \mathrm{C}$ for $2 \mathrm{~min}$ and washed (twice, 5 minutes each time) with $10 \mathrm{mM}$ phosphate buffer saline containing $0.15 \mathrm{M} \mathrm{NaCl}$ (PBS). Afterwards, tissue slices were incubated with lectins- $\mathrm{AE}\left(100 \mu \mathrm{L}-100 \mu \mathrm{g} \mathrm{mL}^{-1}\right)$ for $2 \mathrm{~h}$ at $4^{\circ} \mathrm{C}$ followed by washings $(3 \times 5 \mathrm{~min})$ with $100 \mathrm{~mL}$ of PBS. The area corresponding to the tissue section (squareshaped) was defined as $0.25 \mathrm{~cm}^{2}$. Then, the tissues were cut and transferred to polypropylene test tubes containing $50 \mu \mathrm{L}$ of PBS. Finally, solutions of $0.5 \% \mathrm{H}_{2} \mathrm{O}_{2}$ in $0.1 \mathrm{~N} \mathrm{HNO}_{3}(50 \mu \mathrm{L})$ and $0.25 \mathrm{M} \mathrm{NaOH}(50 \mu \mathrm{L})$ were added for chemiluminescent measurement using a luminometer Modulus Single Tube 9200-001 (Turner BioSystems, USA). The emission intensity was determined as relative light units (RLU) with a counting time of 5 seconds per sample. Triplicate measurements were carried out throughout this study. Lectin binding inhibition assays were accomplished by incubating each lectin solution with $300 \mathrm{mM}$ methyl- $\alpha$-D-mannoside (Con A), D-galactose (PNA), $\alpha$-L-fucose (UEA-I), and n-acetylneuraminic acid (MAA) for $45 \mathrm{~min}$ at $25^{\circ} \mathrm{C}$ prior to their incubation with tissues. The following steps were as described previously for the binding protocol.

2.5. Statistical Analysis. The software OriginPro 8 (OriginLab Corporation, One Roundhouse Plaza, Northampton, MA, USA) was used for the statistical analysis, and data were expressed as mean \pm standard deviation (s.d.). Obtained data 
were compared using ANOVA and parametric statistical test of Tukey $(P<0.05)$ through SigmaPlot (CA, USA).

\section{Results}

Lectins conjugated to acridinium ester (Con A-AE, PNA-AE, UEA-AE, and MAA-AE) were collected by Sephadex G-25 chromatography and their profiles were identical to those previously reported [15]. The superposition of the protein and chemiluminescence peaks indicated that all studied lectins were labeled with the AE. The lectin derivatives were also capable of recognizing their specific carbohydrates according to the hemagglutinating activity.

These lectin derivatives were used to investigate the glycophenotype of cutaneous tumor tissues and the results are displayed in Figure 1. Lower expression of $\alpha$-D-glucose/mannose was presented for all tumors compared with the normal tissue. AK, KA, SCC, and BCC showed values of RLU equal to $143,694 \pm 28,626 \mathrm{RLU} ; 140,704 \pm 29,009 \mathrm{RLU}$; $148,238 \pm 38,333 \mathrm{RLU}$, and 134,007 \pm 30,537 RLU, respectively, whereas the normal tissue was $271,435 \pm 64,329$ RLU. The $\alpha$-L-fucose expression pattern was also lower for cutaneous tumors (RLU values of $11,831 \pm 1,935$ RLU; 28,773 \pm 6,468 RLU; 14,586 \pm 3,464 RLU, and 13,880 \pm 2,926 RLU for AK, KA, SCC, and BCC, resp.) compared with the normal epidermis $(33,743 \pm 5,182 \mathrm{RLU})$. On the other hand, they presented higher expression of Gal- $\beta(1-3)$-GalNAc compared with the normal skin tissues. AK, KA, SCC, and BCC presented RLU values of 23,766 $\pm 2,525$ RLU; 32,567 \pm 6,127 RLU; 31,172 \pm 5,134 RLU; and 18,007 \pm 4,618 RLU, respectively, whereas a value of 7,567 $\pm 1,799$ RLU was found for the normal tissue. Actinic keratosis and SCC exhibited higher expression of Neu5Ac- $\alpha(2,3)$ Gal than normal epidermis $(35,687 \pm$ 8,226 RLU, 65,370 \pm 16,811 RLU, and 44,864 \pm 11,644 RLU, resp.). However, KA $(26,927 \pm 6,942 \mathrm{RLU})$ and $\mathrm{BCC}(29,836$ $\pm 6,179 \mathrm{RLU})$ showed equal RLU values compared with the normal tissue. The standard deviation of all measurements varied from $10.6 \%$ to $25.9 \%$ of the mean value.

For all lectins, the mean among RLU values of cutaneous tumors and normal epidermis was significantly different, as observed using parametric statistical test of Tukey. However, statistically significant variations were not observed among RLU values of cutaneous tumors labeled with ConA-AE, AK and KA labeled with PNA-AE, AK and SCC labeled with UEA-AE, and BCC and KA labeled with MAA-AE. LectinsAE inhibition binding assay using specifics carbohydrates $(300 \mathrm{mM}$ ) resulted in a decrease in RLU values (from 65\% to $93 \%$ ) indicating that unspecific binding between the conjugates and cell surface molecules did not occur.

\section{Discussion}

In our laboratory, the acridinium ester was used as a marker to Trypanosoma cruzi and Schistosoma mansoni antigens in chemiluminescent immunoassay. By this method, small amounts (nanogram scale) of circulating antibodies were detected in the patients' serum [21]. The glycocode of normal, fibroadenoma, and invasive duct carcinoma tissues was

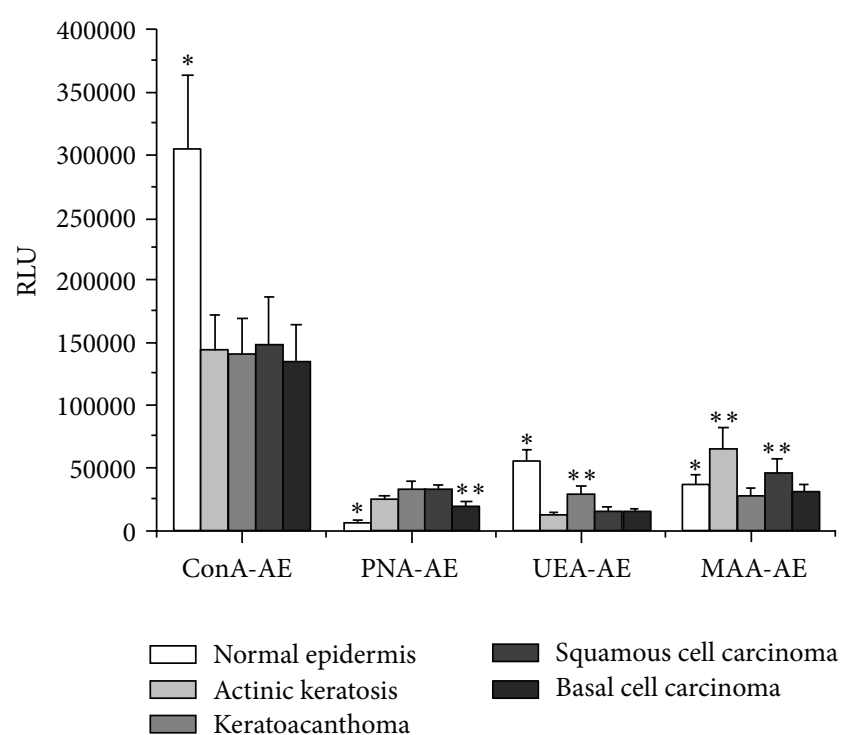

FIGURE 1: Comparison between the chemiluminescence of normal epidermis (NE, $n=14$ ), actinic keratosis (AK, $n=9$ ), keratoacanthoma (KA, $n=13$ ), squamous cell carcinoma (SCC, $n=$ 13 ), and basal cell carcinoma (BCC, $n=17$ ) labeled with Con AAE, PNA-AE, UEA-AE, and MAA-AE. (*) Statistically significant variations were observed among RLU values of cutaneous tumors and normal epidermis. $(* *)$ Statistically significant variations were observed among RLU values of cutaneous tumors.

investigated using lectins labeled with AE $[15,22]$. Anti-HER$2-\mathrm{AE}$ allowed a reduction in the subjectivity in prognostic and predictive information intrinsic to Her-2 status evaluation in breast tumors [23].

Cell surface glycans are highly related to cell-cell communication, host-pathogen interaction, and cell matrix interactions [24]. Tumor invasion is dependent on a loss of intercellular adhesion and transmigration of cells through the basement membrane (BM) as well as the surrounding extracellular matrix (ECM) [25]. Metastasis is a multistep phenomenon, which involves the loosening of the tumor cells from the primary tumor, the degradation of the extracellular matrix, and the invasion of blood vessels at the site of the primary tumor [6]. These steps require adhesive interactions, which are mediated by cell surface glycans and their interactions with endogenous carbohydrate binding proteins (lectins). Aberrant glycosylation is a key feature of malignant transformation and the glycans involved influence the adhesive interactions of cancer cells often providing favorable conditions for tumor dissemination [26]. The molecular organization and the stability of adherent junctions formation are influenced by the presence of altered glycans on the cell surface, phenotypic change commonly observed in malignancy [27].

Alterations in the expression of glycophenotype between benign and malignant skin lesions have been previously reported through lectin histochemistry and computer image analysis [8]. It is worthwhile to register that they did not compare with normal epidermis and included trichoepithelioma and seborrheic keratosis that were not studied in this work. 
These authors reported higher expression of $\alpha$-D-glucose/ mannose (except in SCC) and D-galactose residues in cutaneous tumors. The chemiluminescent $\alpha$-D-glucose/mannose detection (Con A-AE) corroborated these findings but they were statistically lower than those found for the normal epidermis. They also found high D-galactose residues (PNA) as well as our results except that lower RLU was detected compared to the normal epidermis. Another contradiction was found as far as fucose is concerned. Here fucose was chemiluminescently detected in the tumors that were statistically lower than that estimated for normal epidermis. Therefore, these lectins can be used as markers for distinction among skin lesions; however, the chemiluminescent approach may be more sensitive than that based on computer image analysis of lectin histochemistry.

Smetana et al. [28] reported that laminins, a principal component of $\mathrm{BM}$, exhibit unique saccharidic epitopes (mannose-rich oligosaccharides). Therefore, aberrant $\alpha$-Dglucose/mannose expression in this protein may modify the adhesive interactions between transformed cells, contributing for the detachment of cancer cells from the primary tumor mass and the acquisition of a more motile and invasive phenotype.

Several common structural changes occur in tumor glycans and can affect interactions between tumor cell-surface glycans and endogenous lectins, which may determine the metastatic potential of the tumor cell, including increases in the level of truncation and branching of structures as well as an increased expression of unusual terminal sequences [29]. These changes often result in an increased exposure of terminal galactose residues such as those found in the cancer-associated $\mathrm{T}$ antigen (Gal $\beta 1-3 \mathrm{GalNAc}$ ) and the Lewis $\mathrm{X}$ trisaccharide (Gal $\beta 1$ 4(Fuc $\alpha 1-3)$ GlcNAc) [30]. The higher expression of galactose residues observed by high RLU could be related to the potential role of galactose ligands in tumor cell metastasis by the correlation between increased expression of galectin, a family of galactose binding proteins, and the ability of many tumor cell types to metastasize [31].

Fucosylation is one of the most common modifications involving oligosaccharides on glycoproteins or glycolipids. It regulates the biological functions of adhesion molecules and growth factor receptors [32]. In this study, fucosylation pattern changes were observed by the decrease of chemiluminescence signal using UEA-I conjugated to AE for the labeling of cutaneous tumors. AK showed fucosylation pattern similar to malignant lesions and different when compared to benign lesion (KA). This suggests a biochemical similarity with malignant neoplasms and supports the studies claiming that $\mathrm{AK}$ and CEC are the same lesion in different degrees of development.

It is known that both integrins and E-cadherin are associated with cancer cells characteristics through regulation of the cell-extracellular matrix interaction and homotypic cellcell adhesion, respectively [33]. Zhao et al. [34] showed that core fucosylation is essential for the function of $\alpha 3 \beta 1$ integrin, a protein that connects many biological functions such as development, control of cell proliferation, and protection against apoptosis and malignant transformation. Osumi et al. [35] suggested a possible core fucosylation role in cellcell adhesion regulation in cancer. Therefore, based on the information above, it can be concluded that fucose would be involved in the biological behavior of cancer cells through functions regulation of many membrane associated proteins.

Sialic acids (Sias) are typically the outermost monosaccharide units on the glycan chains of glycolipids and glycoproteins and usually occur as a terminal component at the nonreducing end of their carbohydrate chains [36]. Due to its terminal localization on glycans and the variety of linkages to the underlying sugar chain, sialic acid has been utilized by a wide variety of Sia-binding proteins, mainly viral and bacterial pathogens proteins, selectins, and siglecs [37].

The increase in the expression of Neu5Ac- $\alpha(2,3) \mathrm{Gal}$ between benign and malignant lesions of skin, AK, and SCC, respectively, was observed by the increase of RLU values. The differences in the sialylation degree of glycoconjugates on a tumor cell surface of SCC may play an important role in the process of cell malignization and metastasis [38]. Vural et al. [39] reported the increase of total sialic acid (TSA) levels between patients with AK and controls, probably related to increased turnover of cells [40]. Plzák et al. [13] observed that differentiated squamous cell carcinoma expresses 2,3linked-NeuAc residues (recognized by lectin MAA) and the poorly differentiated squamous cell carcinoma 2,6-linkedNeuAc (recognized by Sambucus nigra agglutinin).

Sialyl-glycoconjugates may regulate the interaction of cancer cells with other cells and with the cell matrix. These molecules may be responsible for adhesion as well as antiadhesion and for extending the survival time of cancer cells in the blood stream. Moreover, sialic acid may also be involved in growth regulation [41].

From the results presented in this work one can assume that the chemiluminescent lectin-histochemistry approach allows the glycophenotype direct quantitative evaluation of skin tumors combining the specificity lectincarbohydrates interaction and sensitivity of chemiluminescent assay. Despite that the number of analyzed samples ( $n$ values) does not permit a definitive assumption as far as diagnosis is concerned the statistical analyses showed glycophenotype alterations according to the cutaneous tumors. Furthermore, although paraffin-embedded skin fragments were obtained from different individuals and sections were cut from them, acceptable mean dispersion values (standard variation range of $10.6 \%-25.9 \%)$ were observed. Higher expression of $\beta$-Gal (1-3)-GalNAc and Neu5Ac- $\alpha(2,3) \mathrm{Gal}$ as well as lower expression of $\alpha$-D-glucose/mannose and $\alpha$-Lfucose residues was evidenced by differences in RLU values. These results confirm the importance of lectins as potential biomarkers for detection of changes in glycophenotype of skin neoplasms. Furthermore, this procedure is an effective tool to eliminate subjective analyses of microscopic preparations.

\section{Acknowledgments}

This work was supported by CNPq, CAPES, and FACEPE (Brazilian scientific agencies). The authors thank Carmelita Bezerra de Lima Cavalcanti and Otaviano Tavares da Costa 
for technical assistances. They also thank Dr. Tatiana Caloi and Dr. Mariana Silva for providing the human normal epidermis fragments and the cutaneous tumor histopathological diagnoses, respectively.

\section{References}

[1] H. Ghazarian, B. Idoni, and S. B. Oppenheimer, "A glycobiology review: carbohydrates, lectins and implications in cancer therapeutics," Acta Histochemica, vol. 113, no. 3, pp. 236-247, 2011.

[2] B. Adamczyk, T. Tharmalingam, and P. M. Rudd, "Glycans as cancer biomarkers," Biochimica et Biophysica Acta, vol. 1820, no. 9, pp. 1347-1353, 2012.

[3] Y. Mechref, Y. Hu, A. Garcia, and A. Hussein, "Identifying cancer biomarkers by mass spectrometry-based glycomics," Electrophoresis, vol. 33, no. 12, pp. 1755-1767, 2012.

[4] M. M. Fuster and J. D. Esko, "The sweet and sour of cancer: glycans as novel therapeutic targets," Nature Reviews Cancer, vol. 5, no. 7, pp. 526-542, 2005.

[5] M. Herling, J. Knolle, H. Bahn et al., "Glycohistochemical monitoring of chemically induced sarcomas at different stages of tumorigenesis," In Vivo, vol. 14, no. 4, pp. 499-506, 2000.

[6] A. Thies, I. Moll, J. Berger, and U. Schumacher, "Lectin binding to cutaneous malignant melanoma: HPA is associated with metastasis formation," British Journal of Cancer, vol. 84, no. 6, pp. 819-823, 2001.

[7] A. Thies, A. Berlin, G. Brunner et al., "Glycoconjugate profiling of primary melanoma and its sentinel node and distant metastases: implications for diagnosis and pathophysiology of metastases," Cancer Letters, vol. 248, no. 1, pp. 68-80, 2007.

[8] M. R. Melo Júnior, J. L. S. Araújo Filho, V. J. R. M. Patu, M. C. F. P. Machado, E. I. C. Beltrão, and L. B. Carvalho Jnior, "Digital image analysis of skin neoplasms evaluated by lectin histochemistry: potential marker to biochemical alterations and tumour differential diagnosis," Jornal Brasileiro de Patologia e Medicina Laboratorial, vol. 42, no. 6, pp. 455-460, 2006.

[9] T. Basarab, G. Orchard, and R. Russell-Jones, "The use of immunostaining for bcl-2 and CD34 and the lectin peanut agglutinin in differentiating between basal cell carcinomas and trichoepitheliomas," American Journal of Dermatopathology, vol. 20, no. 5, pp. 448-452, 1998.

[10] A. Roda, M. Mirasoli, D. Melucci, and P. Reschiglian, "Toward multianalyte immunoassays: a flow-assisted, solid-phase format with chemiluminescence detection," Clinical Chemistry, vol. 51, no. 10, pp. 1993-1995, 2005.

[11] J. L. S. Araújo Filh, M. R. Melo Júnior, and L. B. Carvalho Júnior, "Potential applications of the chemiluminescent methods in tumoral diseases investigation," International Journal of Pharma \& Bio Sciences, vol. 2, no. 2, pp. 392-400, 2011.

[12] A. Natrajan, D. Sharpe, J. Costello, and Q. Jiang, "Enhanced immunoassay sensitivity using chemiluminescent acridinium esters with increased light output," Analytical Biochemistry, vol. 406, no. 2, pp. 204-213, 2011.

[13] J. Plzák, K. Smetana Jr., M. Chovanec, and J. Betka, "Glycobiology of head and neck squamous epithelia and carcinomas," Oto-Rhino-Laryngolog, vol. 67, no. 2, pp. 61-69, 2005.

[14] A. Fan, Z. Cao, H. Li, M. Kai, and J. Lu, "Chemiluminescence platforms in immunoassay and DNA analyses," Analytical Sciences, vol. 25, no. 5, pp. 587-597, 2009.

[15] V. P. Brustein, C. L. B. Cavalcanti, M. R. Melo Júnior, M. T. Correia, E. I. C. Beltrão, and L. B. Carvalho Júnior, "Chemiluminescent detection of carbohydrates in the tumoral breast diseases," Applied Biochemistry and Biotechnology, vol. 166, no. 2, pp. 268-275, 2011.

[16] L. J. Kricka, "Clinical applications of chemiluminescence," Analytica Chimica Acta, vol. 500, no. 1-2, pp. 279-286, 2003.

[17] D. W. King, W. J. Cooper, S. A. Rusak et al., "Flow injection analysis of $\mathrm{H}_{2} \mathrm{O}_{2}$ in natural waters using acridinium ester chemiluminescence: method development and optimization using a kinetic model," Analytical Chemistry, vol. 79, no. 11, pp. 41694176, 2007.

[18] C. Ricotti, N. Bouzari, A. Agadi, and C. J. Cockerell, "Malignant skin neoplasms," Medical Clinics of North America, vol. 93, no. 6, pp. 1241-1264, 2009.

[19] E. I. Beltrão, M. T. S. Correia, J. F. Silva, and L. C. B. B. Coelho, "Binding evaluation of Isoform 1 from Cratyliamollislectin to human mammary tissues," Applied Biochemistry and Biotechnology, vol. 74, no. 3, pp. 125-134, 1998.

[20] O. H. Lowry, N. J. Rosebrough, A. L. Farr, and R. J. Randall, "Protein measurement with the Folin phenol reagent," The Journal of Biological Chemistry, vol. 193, no. 1, pp. 265-275, 1951.

[21] R. A. L. Coêlho, G. A. Jaques, A. D. Barbosa et al., "Magnetic polysiloxane-polyvinyl alcohol composite as solid-phase in chemiluminescent assays," Biotechnology Letters, vol. 24, no. 20, pp. 1705-1708, 2002.

[22] L. M. Campos, C. L. B. Cavalcanti, J. L. Lima-Filho, L. B. Carvalho, and E. I. C. Beltrão, "Acridinium ester conjugated to lectin as chemiluminescent histochemistry marker," Biomarkers, vol. 11, no. 5, pp. 480-484, 2006.

[23] M. J. B. M. Rêgo, M. F. Cordeiro, C. L. B. Cavalcanti, L. B. Carvalho Júnior, and E. I. C. Beltrão, "Imunohistoquimiluminescence detection: a quantitative tool in breast cancer HER-2 status evaluation," Disease Markers, vol. 34, no. 5, pp. 373-377, 2013.

[24] S. M. Zhou, L. Cheng, S. J. Guo, H. Zhu, and S. C. Tao, "Lectin microarrays: a powerful tool for glycan-based biomarker discovery," Combinatorial Chemistry and High Throughput Screening, vol. 14, no. 8, pp. 711-719, 2011.

[25] B. Schnegelsberg, U. Schumacher, and U. Valentiner, "Lectin histochemistry of metastasizing and non-metastasizing breast and colon cancer cells," Anticancer Research, vol. 31, no. 5, pp. 1589-1597, 2011.

[26] N. D. S. Rambaruth and M. V. Dwek, "Cell surface glycan-lectin interactions in tumor metastasis," Acta Histochemica, vol. 113, no. 6, pp. 591-600, 2011.

[27] B. T. Jamal, M. Nita-Lazar, Z. Gao, B. Amin, J. Walker, and M. A. Kukuruzinska, "N-glycosilation status of E-cadherin controls cytoskeletal dynamics through the organization of distinct $\beta$ catenin and $\gamma$-catenin-containing AJs," Journal of Cell Health and Cytoskeleton, vol. 2009, no. 1, pp. 67-80, 2009.

[28] K. Smetana Jr., J. Plzák, B. Dvoránková, and Z. Holíková, "Functional consequences of the glycophenotype of squamous epithelia-practical employment," Folia Biologica, vol. 49, no. 3, pp. 118-127, 2003.

[29] Y. J. Kim and A. Varki, "Perspectives on the significance of altered glycosylation of glycoproteins in cancer," Glycoconjugate Journal, vol. 14, no. 5, pp. 569-576, 1997.

[30] A. S. Powlesland, P. G. Hitchen, S. Parry et al., "Targeted glycoproteomic identification of cancer cell glycosylation," Glycobiology, vol. 19, no. 8, pp. 899-909, 2009.

[31] Y. Takenaka, T. Fukumori, and A. Raz, "Galectin-3 and metastasis,” Glycoconjugate Journal, vol. 19, no. 7-9, pp. 543-549, 2002. 
[32] E. Miyoshi, K. Moriwaki, and T. Nakagawa, "Biological function of fucosylation in cancer biology," Journal of Biochemistry, vol. 143, no. 6, pp. 725-729, 2008.

[33] K. Moriwaki and E. Miyoshi, "Fucosylation and gastrointestinal cancer," World Journal of Hepatology, vol. 2, no. 4, pp. 151-161, 2010.

[34] Y. Zhao, S. Itoh, X. Wang et al., "Deletion of core fucosylation on $\alpha 3 \beta 1$ integrin down-regulates its functions," Journal of Biological Chemistry, vol. 281, no. 50, pp. 38343-38350, 2006.

[35] D. Osumi, M. Takahashi, E. Miyoshi et al., "Core fucosylation of E-cadherin enhances cell-cell adhesion in human colon carcinoma WiDr cells," Cancer Science, vol. 100, no. 5, pp. 888-895, 2009.

[36] F. Lehmann, E. Tiralongo, and J. Tiralongo, "Sialic acid-specific lectins: occurrence, specificity and function," Cellular and Molecular Life Sciences, vol. 63, no. 12, pp. 1331-1354, 2006.

[37] N. M. Varki and A. Varki, "Diversity in cell surface sialic acid presentations: implications for biology and disease," Laboratory Investigation, vol. 87, no. 9, pp. 851-857, 2007.

[38] W. Bergler, F. Riedel, R. Schwartz-Albiez, H. J. Gross, and K. Hörmann, "A new histobiochemical method to analyze sialylation on cell-surface glycoproteins of head and neck squamous-cell carcinomas," European Archives of Oto-Rhino-Laryngology, vol. 254, no. 9-10, pp. 437-441, 1997.

[39] P. Vural, M. Canbaz, and D. Selçuki, "Total and lipid-bound Sialic acid levels in actinic keratosis and basal cell carcinoma," Turkish Journal of Medical Sciences, vol. 29, pp. 419-423, 1999.

[40] S. I. Hakamory, "Tumor-associated carbohydrate antigens," Annual Review of Immunology, vol. 2, pp. 103-126, 1984.

[41] K. L. Carraway, N. Fregien, K. L. Carraway III, and C. A. C. Carraway, "Tumor sialomucin complexes as tumor antigens and modulators of cellular interactions and proliferation," Journal of Cell Science, vol. 103, no. 2, pp. 299-307, 1992. 


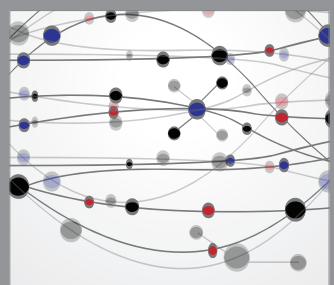

The Scientific World Journal
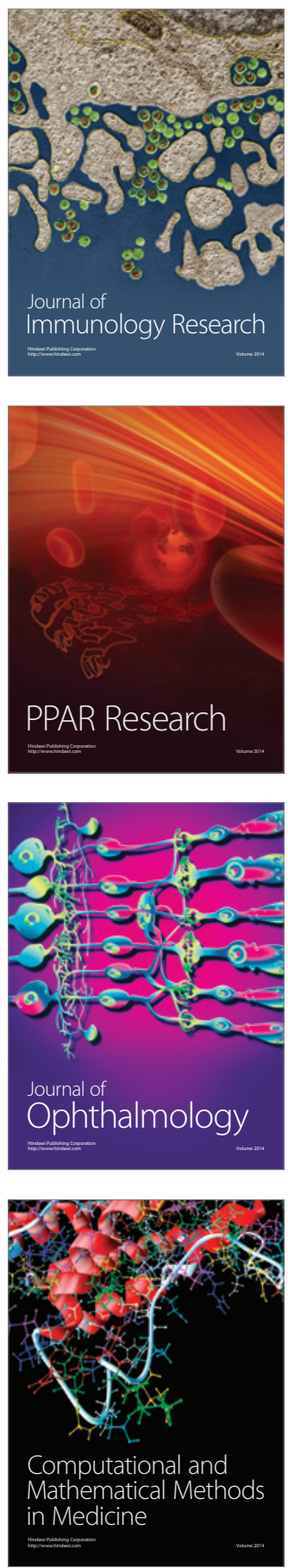

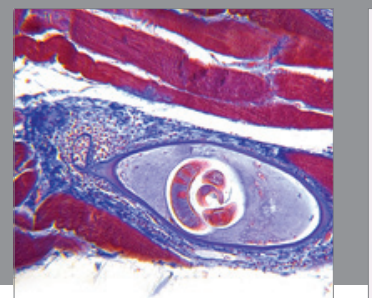

Gastroenterology

Research and Practice
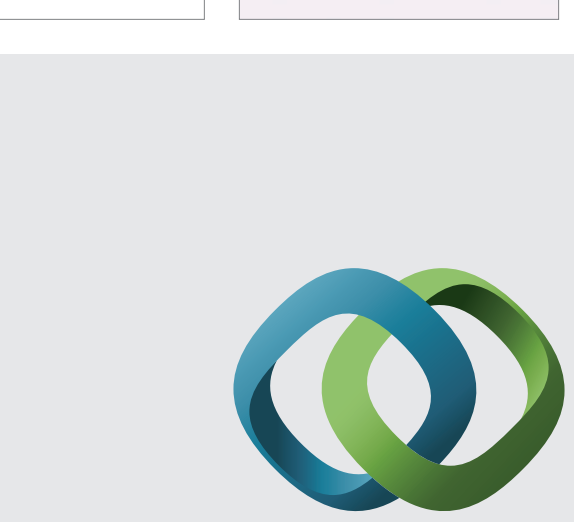

\section{Hindawi}

Submit your manuscripts at

http://www.hindawi.com
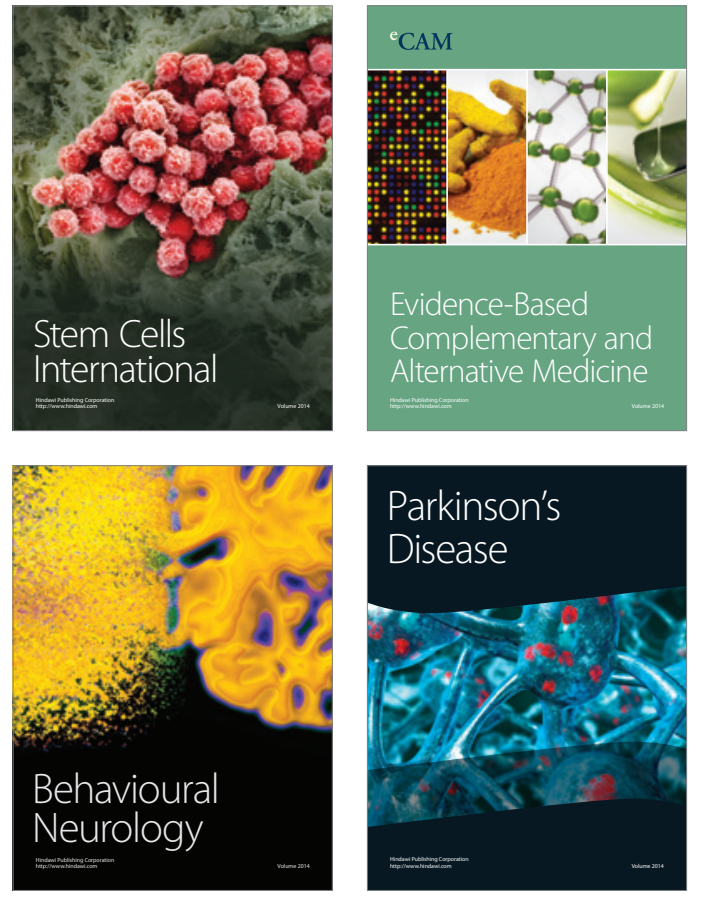
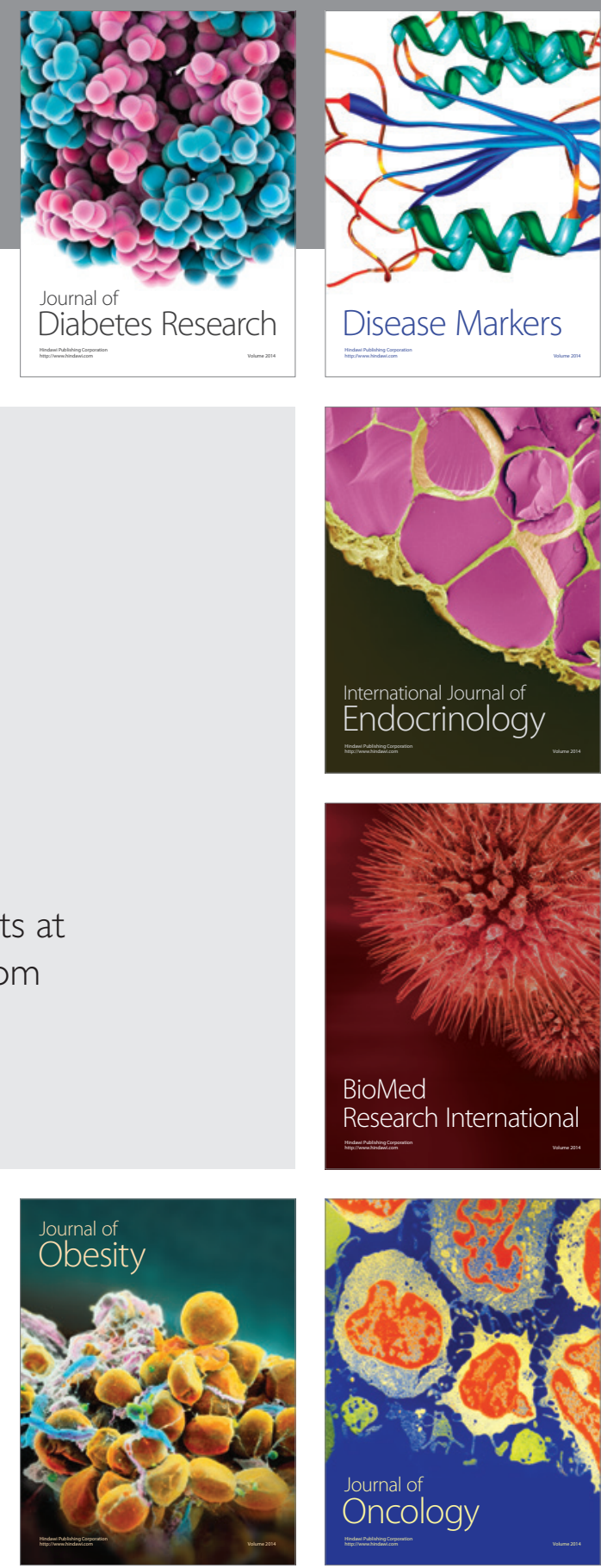

Disease Markers
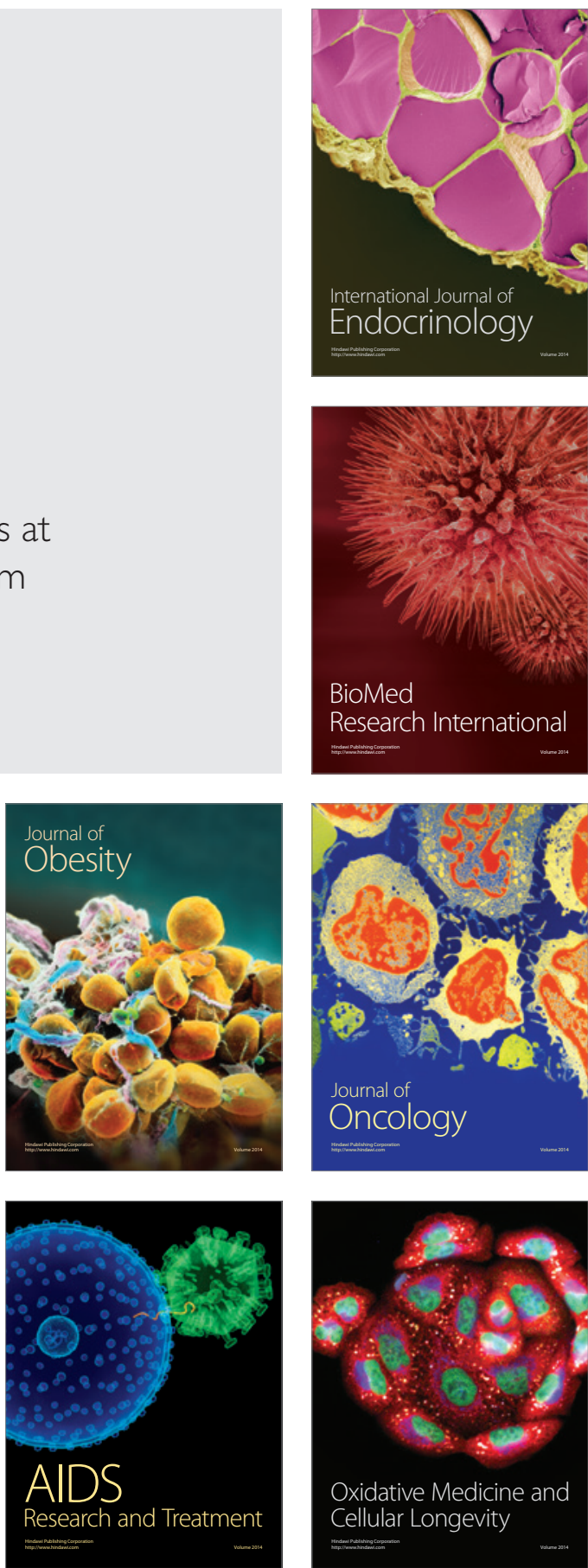